\title{
EDITORIAL
}

\section{New Curriculum in BSMMU}

Though very late The Bangabandhu Sheikh Mujib Medical University has adopted the new competency based curriculum, popularly known as residency program from this year. The key aspect of the new curriculum is that it is a competency and outcome based curriculum. The residency program is learner centered as opposed to traditional teacher centered. Self directed learning is the basis of attaining competencies where the learners will be decision makers and the teacher's role will be to guide. The residents will be monitored from various corners, deficiencies will be identified at appropriate level and corrective measures will be taken then and then. Through this program the students will attain seven broad competencies: Medical expert, communicator, collaborator, manager/ team leader, health advocate, scholar, and professional. The end product will be a good clinical decision maker with humanistic and empathic attitude. In the existing curriculum the students take the training which is unstructured and not well supervised. After the training the students undergo basic science teaching followed by a period of course and finally appear in the examination to tell him/her pass or fail. The student does not know even in the whole period of training where is his/her deficiency? It is expected that the thinks will be changed in the new curriculum. The academic part and training part will be integrated. The whole training will be structured and will be fully supervised. It is also expected that there will be gross change in the assessment system. There will be system of monitoring of the supervisors also.
Residency program is not a new thing. In many parts of the worlds including our neighboring countries doctors are being trained through the residency program. Actually the residency program was started in this university in 1991; but there was premature death of the program and because of this our teaching training program lag behind by at least 20 years. We hope this time this do not suffer the same fate. So far we know a group of dedicated teachers are doing hard to make the residency program a successful one. By this time they become able to prepare a clear cut concept paper, develop the curriculum framework, problem oriented medical record form, logbook, and portfolio and assessment system. Many things are left to do. Teachers' needs much more oriented to the new program. They need motivation to cope with the new environment. The program itself needs monitoring; lapses and weaknesses should be identified by a strong system of evaluation and appropriate corrective measures should be taken timely. Once the backbone becomes strong then no one will be able to break it up. Let us all work together to make the residency program a successful one so that we can be pioneer in the field of medical education.

\author{
Prof MA Jalil Chowdhury \\ Professor, Department of Medicine \\ BSMMU, Dhaka
}

